The policy response to home-grown terrorism: Reconceptualising Prevent and Resilience as collective resistance

\begin{abstract}
The policy response to home-grown terrorism focuses attention on the root causes of terrorism. Such soft approaches to countering terrorism are a necessary element of an effective and comprehensive strategy. The United Kingdom's Prevent strategy, Australia's Resilience approach and the United State's diminish element all share a focus on countering violent extremism on the home front through a policy approach that promotes democratic values, social harmony and active participation of Muslim communities. This paper argues that such responses are informed by flawed assumptions that have little or no evidentiary basis and calls for a re-conceptualisation of soft counter terrorism as collective resistance against terrorism. It presents the preliminary findings of a qualitative research project that explores how a citizen driven initiative to build a peace park on the site of the Bali 2002 terrorist bombings constructs a counter-narrative to terrorist propaganda and contributes to sustainable and long term soft counter-terrorism.
\end{abstract}

Key words: counter terrorism policy, soft counter-terrorism, collective resistance 
The policy response to home-grown terrorism: Reconceptualising Prevent and Resilience as collective resistance

The strategic model of terrorism links terrorism to social, economic and political inequalities and posits that such disparities motivate violent dissent (Victoroff, 2005). Attempts to understand the root causes of terrorism within the disciplines of psychology and sociology theorise that terrorism, as an individual and group behaviour, is targeted violence primarily driven by the need to avenge perceived injustices or past trauma or perceived grievance (Crenshaw, 2003). Claims by terrorist groups that violence is a last resort in contexts of state repression may, in part, substantiate this approach to terrorism. At least one account of the life of al- Qaeda's, Ayman al-Zawahiri claims that he only turned to violence after being tortured during his incarceration at Egypt's notorious Torah prison. Similarly, the Egyptian Muslim Brotherhood initially followed a path of peaceful Da'wa (the Islamic tradition of spreading Islam through words and deeds). Gamal Abdul Nasser's campaign of repression severely restricted the Brotherhood's activities and delegitimized its political aspirations contributing to the group seeking alternative, violent measures for achieving their political goals. Relative Deprivation Theory (RDT) which proposes that individuals who perceive themselves to be as part of disadvantaged group will take action to improve their conditions; Frustration- aggression hypothesis, the notion that individuals and groups become violent in response to protracted campaigns of economic, social or political oppression and; oppression theory which posits that people turn to violence in oppressed conditions, have all been used to explain dissident terrorism and violence.

Other examinations of the causal factors of terrorism interpret suicide terrorism as a form of collective action. According to Robert Pape's (2006) logic of suicide 
terrorism, suicide attackers act altruistically for the greater good of the collective. Suicide terrorism garners popular support when it is adopted as a strategy by groups in occupied territories who aspire to self-governance. As such, suicide terrorism is constructed as a selfless involvement in a collective pursuit and in response to either individual or collective trauma.

\section{Soft Counter Terrorism}

Based on the above understandings of the underlying causes of terrorism, international efforts to counter terrorism through soft approaches target economic development, political reform, and the promotion of social and political equality in countries where terrorist groups are known to have significant public support. The 9/11 Commission Report for example, supports the use of foreign aid as a means of addressing the proliferation of terrorist ideologies among the poor and disenfranchised. Such approaches are largely premised on the assumption that poverty and social or political grievances manifest in terrorist movements and public support for terrorist activities.

In September 2006, UN Member states adopted the United Nations Global CounterTerrorism Strategy. The strategy, in the form of a resolution and an annexed Plan of Action, aims at enhancing national, regional and international efforts to counter terrorism with a focus on international collaboration to combat terrorism. The adoption of the counterterrorism strategy by the UN member states represents the first time that all member states have agreed on a common operational and strategic approach to dealing with terrorism. Member states that adopted the strategy reaffirmed their commitment to combating terrorism and to implementing measures to address the conditions under which terrorism flourishes and to strengthening the 
collective capacity of the UN to prevent terrorism. The UN counter terrorism strategy includes collective counter- terrorism measures that involve civil society, regional and sub-regional organisations, and the private sector.

Crocker, Hampson and Aall (2011) describe contemporary efforts to address new and complex security challenges as collective conflict management. The authors build on early concepts of collective conflict management originally proposed by Haas and further developed by Lepgold, Weiss and Diehl. These early conceptualisations were applied to peace keeping collaborative programs between NATO and the United Nations. The traditional concept of collective conflict management focussed on collaborative participation in formalised arrangements between international and regional organisations and individual states. Crocker, Hampson and Aall argue for a re-conceptualisation and broadening of collective conflict management in the contemporary security context characterised by diverse and fragmented security challenges. Their broadened conceptualisation of collective conflict management focuses on two inclusions into the traditional concept of collective conflict management: 1. the inclusive participation of civil society groups, professional bodies and task-specific international bodies and 2. the inclusion of ad hoc, informal and improvised collective action measures. Of particular interest is the authors' argument that global security institutions such as the UN and NATO are limited in their capacity to address the complexity of the current security climate. They propose that "Instead of looking to a new institution or a new set of responsibilities for an existing institution, we need to recognize that new collaborative patterns of behaviour are becoming apparent in the conflict management field" (p. 45). Crocker, Hampson and Aall offer three different case studies of contemporary conflict management in action. All three involve cooperative participation by private industry, regional and 
transnational task specific forces, inter-governmental organisations and civil society organisations representing diverse security interests. These examples, as the authors assert, are typical of an emerging trend in international security to respond to security problems in ways that involve diverse stakeholders in informal collective arrangements. At least one of the case studies, that of the Liberia peace process includes local, community based groups in collective conflict management.

Alongside the shift in collective conflict management described by Crocker et al as a response to diverse and complex security problems, governments have attempted to harness un-institutionalised, community based and informal strategies against terrorism. The national security and counter terrorism strategies adopted by governments including Australia and the United Kingdom, to name just two, incorporate soft approaches and recognise the role that communities play in a comprehensive and multi-causal approach to combatting terrorism. Most commonly this is expressed in terms of building community resilience to violent extremism and terrorism.

Australia's counterterrorism approach outlined in The Counter Terrorism White Paper: Securing Australia, Protecting our Community (2010) describes four elements: Analysis, Protection, Response and Resilience. Resilience in the Australian strategy is 'building a strong and resilient Australian community to resist the development of any form of violent extremism and terrorism on the home front'.

The United Kingdom's approach is described in Contest: The United Kingdom's Strategy for Countering International Terrorism. In 2009, the Home Office released the second version of Contest, known as Contest 2. The strategy consists of four strands: Pursue, Prevent, Protect and Prepare. Prevent strategies are designed to address religious extremism and engagement with terrorist ideologies by promoting 
social cohesion and integration. In 2011, a review of the Prevent strategy was prompted by recognition of the need to clearly distinguish between the functions of countering terrorism from promoting social cohesion and integration. The review found that the Prevent program was inherently flawed because it conflated policies of integration and cohesion with counter terrorism policies and hence was ineffective in addressing extremism and radicalisation. The review recommended that a new Prevent strategy focus primarily on the aim of stopping people from becoming terrorists or supporting terrorism with a clear separation from the aims of social cohesion and integration (Bowers, 2011).

In 2011, the United States announced a refocussing of its counter terrorism strategy with an emphasis on preventing the diffusion of extremist ideologies within the United States. The 2011 National Strategy for Counterterrorism has four guiding principles, one of which is building a culture of resilience. This principle emphasises collective resilience to the terrorist threat and collective recovery from the economic and psychological impacts of a terrorist attack The Strategy introduces a new focus on the homeland that was lacking in previous iterations of the US counter terrorism approach. The 2003 National Strategy for Combating Terrorism focussed on four elements of defeating, denying, diminishing and defending. The diminishing element emphasised international partnerships to address conditions in which terrorism flourishes and de-legitimising terrorism through public information initiatives (Perl, 2005). While this element remains an overarching goal in the 2011 Strategy, the strategy focuses the need to apply the diminish goal to domestic audiences through programs that engage communities against "al-Qa'ida inspired radicalization, recruitment, and mobilization to violence" (p. 11). 
While there appears to be significant support for community level collective measures against terrorism there is an emerging debate that questions the premise of strategies such as Prevent and Resilience. In particular questions have been raised about the validity and relevance of strategies that seek to promote inclusivity and social harmony to counter terrorism efforts. Strategies that aim to prevent violent extremism are based on flawed assumptions that frame the policy response to the 'home-grown' terrorism phenomenon:

1. The marginalisation hypothesis

2. The primacy of religion and ideology in terrorism

3. A focus on radicalisation; and

4. A narrow construction of the audience that terrorists seek to influence Collectively, these four assumptions have produced a policy response that has come under criticism for its failure to address the aims of countering terrorism.

\section{The marginalisation hypothesis}

In the aftermath of the London terrorist attacks in 2005, much attention was focused on the motivations of the 'homegrown' suicide bombers: Mohammad Siddique Khan, Hasib Mir Hussain, Shehzad Tanweer (all born and raised in Britain), and Germaine Lindsay. The suggestion that the four young men were isolated from the broader British community and had experienced racism prompted governments in the United Kingdom, Australia and elsewhere to introduce new programs aimed at addressing the marginalisation of Muslim communities, promoting social harmony and enhancing participation by Muslims. The marginalisation hypothesis (elsewhere referred to as the alienation -radicalisation hypothesis; Duffy, 2009) assumes that the London bombers' social and political alienation from the institutions and constructs of British 
society were causal factors for the London suicide bombings and the likely factors behind the new threat of 'homegrown' terrorism in other Western nations.

The marginalisation theory has its roots in political behaviourism. Gurr (1970) argued that radicalisation was motivated by individual frustration at barriers to achievement while Schwartz (1973) embedded radicalisation in the individual's perceived alienation from the political values and institutions of the society in which they live. Both Gurr and Swhartz related their theories to political dissent while other theorists (Hirschi, Mc Cord; Martin and Fitzpatrick) rationalised social deviancy and individual psychopathy through alienation from the norms and values of society (Duffy, 2009). According to this analysis of alienation, individuals are more likely to engage with radical groups when they perceive themselves to be isolated from and not represented by the social constructs of the broader community. Applications of the alienation hypothesis to active involvement in terrorist activities clarify that alienation should be seen as a precondition for terrorist activity as opposed to a precipitant of terrorism (Crenshaw, 1981; Duffy, 2009). This analysis suggests that radicalisation is more likely to occur in pre-existing conditions of alienation (Duffy, 2009). It also suggests that certain individuals and groups are therefore more vulnerable to engage in terrorism because they are alienated or marginalised. A natural progression of this analysis is that involvement in terrorist activities can be addressed through targeted efforts that a) identify vulnerable individuals and groups and b) attempt to integrate these groups by promoting engagement with the political and social structures from which they are presumed to be alienated.

The current debate about the relevance of strategies based on models of radicalisation that pin point marginalisation as a significant contributing factor arises out of the growing recognition that there is little substantiated evidence to support the link 
between social or economic inequality (either real or perceived) and terrorism. The Intelligence and Security Committee Report (2006) into the London terrorist attacks dismissed marginalisation as a the primary motivational force for the London attacks stating that 'the threat is as likely to come from those who appear well assimilated into mainstream UK society, with jobs and young families, as from those within socially or economically deprived sections of the community.' Despite these findings, the original and subsequent iterations of the Prevent strategy continued to incorporate and fund programs that promote participation and integration.

Questions also arise about the cost effectiveness of government funded counterterrorism initiatives that target specific communities, premised on the marginalisation hypothesis. Several studies of terrorism emphasise that terrorists are not alienated or disengaged individuals and that the 'homegrown' phenomenon is not new. The marginalisation hypothesis is rooted in the suggestion that the four London bombers were marginalised from British society and so found some form of identity security in the militant Islamist ideology that supports suicide attacks. This assumes that individuals can only ever identify with one cultural tradition and ignores the fact that the majority of migrants and their offspring have lived peacefully in their host countries by forging new identities that combine both that of the host culture and that of their homeland. One can be, for example, Australian-Singaporean or BritishPakistani or American-Egyptian and vice versa. The marginalisation hypothesis also assumes that political and social isolation from the host society is enough to motivate individuals to violent extremism. If it were, the phenomenon of 'homegrown' terrorism would be much more widespread as many ethnic and religious minorities harbour some feelings of being marginalised from the broader community. While 
marginalisation is a widespread phenomenon, 'homegrown' terrorism is not (Aly, 2011).

\section{Primacy of religion and ideology}

The war on terrorism has often been described as a battle for hearts and minds with specific reference to countering the spread of al Qaeda's ideology. While not contesting the validity of this analysis we are reminded that it was the Anarchists of the 1920's who first coined the term 'propaganda by the deed' (Aly, 2011). In effect, efforts to counter terrorism by countering ideology have resulted in a policy position that exhorts the promotion of 'moderate' Islam over more extreme religious interpretations and singles out Muslim communities. In 2005, the Australian Government introduced the National Action Plan. The Plan had the stated objective to promote "social cohesion, harmony and support the national security imperative in Australia by addressing extremism, the promotion of violence and intolerance, in response to the increased threat of global religious and political terrorism." The National Action Plan specifically singled out Muslim communities for funding programs including education and the training of religious leaders in Australia (Commonwealth of Australia, n.d.).

In 2007, the Rand Corporation released a monograph entitled Building Moderate Muslim Networks. The authors argue that the United States has a critical role to play in enabling networks of moderate Muslims to counter extremist interpretations and sets out a "road map" for the development of moderate Muslim networks based on elements of the US policy of containment during the Cold War. According to this report 'moderate' Muslims are characterised as those who "share the key dimensions of democratic culture. These include support for democracy and internationally 
recognized human rights (including gender equality and freedom of worship), respect for diversity, acceptance of nonsectarian sources of law, and opposition to terrorism and other illegitimate forms of violence" (Rabasa et al., 2007, p. 66).

The policy reaction of promoting moderate Islam is based on an understanding of radicalisation best summarised by Stevens (2009):

Violent extremism takes hold where alternative viewpoints or teachings are weak or ineffectual. Through lack of viable alternatives, a disaffected new generation of home-grown Muslims is being exposed to a corrupting set of doctrines that feeds on those disaffections and presents itself as the explanation, the solution and the sole inheritor of the correct Islamic teachings... Providing a strong and attractive moderate alternative helps fill the doctrinal vacuum and prevents radicalisation. Moderate religious views are conducive to instilling shared values...that help lead to social stability. Taking a hand in fostering moderation helps secure these virtues and combats radicalism. (p. 517)

Efforts to promote 'moderate' Islam as a measure to counter terrorism have been criticized by some Muslims as being a politically contrived attempt at regulating religious practice. Critics of this approach argue that Islam is inherently a moderate religion and that the promotion of moderate Islam is counter- productive because it positions good Muslims over bad Muslims and reinforces the extremist narrative (NBR, 2007). Other critics such as Thomas (2009) contend that social cohesion programs under the banner of counterterrorism that single out Muslim communities are counter-productive to the very aim of social cohesion because they are ethnospecific. 
Arguably the policy reaction of promoting moderate Islam as a counter terrorism strategy reflects the familiar, yet flawed, pattern of Western engagement with the Muslim world. Malley and Harling (2011) argue that the Obama administration's approach to the Middle East is stymied by flawed assumptions about the region. According to Malley and Harling "Washington still sees the Middle East as cleanly divided between two camps: a moderate, pro-American camp that out to be bolstered and a militant, pro-Iranian one that needs to be contained. That conception is wholly divorced from reality." (p. 19). Moderate Islam is constructed as an ideology that is democracy friendly. Moderate Muslims are those who embrace the principles of democracy and liberalism while extremists are those who do not. This division might fit neatly with a government agenda but it completely ignores the complexities of religious and political identities.

An equally pertinent point in building an argument against the approach of promoting 'moderate' Islam is the fact that this approach rests on an assumption that religious ideology is the primary driver of extremist violence (within the context of Islamist terrorism). While there is no denying that religion plays a role in the radicalisation of individuals and groups to commit violent acts, religion is by no means the sole motivation for violent extremism. Stevens (2009) disputes the rationale for strategies to promote moderate Islam in the Prevent component of the UK counter terrorism strategy. He asserts that this arm of the Prevent strategy is based on two flawed assumptions: firstly, that religion is the primary motivator for individuals to join extremist groups; and secondly that government intervention is an effective mechanism for winning hearts and minds. Much of the evidence available suggests that ideology plays a less important role in radicalisation. Thornberry et al's (2003) analysis of delinquent gangs demonstrated that ideological sympathies played a far 
lesser role than group loyalties in motivating violence. Members of radical or extremist groups were therefore more liable to commit acts of violence in defence of the group itself rather than in defence of its ideologies (Duffy, 2009, p. 134). Stevens (2009) constructs his argument somewhat differently and contends that the primary reason for joining radical groups is not religious but the personal benefits associated with group membership. Stevens further argues that assuming that individuals join radical groups because they lack either the opportunity or capacity to engage with viable alternatives is reminiscent of initial reactions to the 'brainwashing' activities of New Age cults in the 1970's. The Prevent strategy, argues Stevens, "is still at the stage of attempting to 'rescue' the brainwashed- a tactic that never worked in the 1970s" (p. 519).

\section{Focus on radicalisation}

The third assumption upon which strategies of Prevent and Resilience are based is the focus on radicalisation. Notwithstanding the contributions of radicalisation studies in establishing radicalisation as a precondition to terrorism an assessment of the value of focussing on radicalisation over and above the aim of countering terrorism is warranted. Australia's National Action Plan fails to make any real connection between radicalisation and terrorism other than acknowledging that radicalisation has the potential to erupt into violence and disruption. The Countering Violent Extremism arm of the Resilience strategy in Australia draws a similarly tenuous link between counter- radicalisation and counter- terrorism stating that the countering violent extremism approach will "reduce the potential for a home grown terrorist attack through building a more resilient Australia that is less vulnerable to the processes of radicalisation and through assisting individuals to disengage from violent extremist influences." Richards (2011) maintains that an emphasis on radicalisation in the 
Prevent strategy has supported a policy response that confounds the counterterrorism agenda with the policy agenda of promoting social cohesion. More importantly, the focus on radicalisation does not distinguish between violent extremism and nonviolent forms of radicalisation such as tacit support for terrorists perceived to have a legitimate cause while rejecting the use of violence. The confusion around the exact scope of radicalisation is cause for concern. Richards rightly asks some pertinent questions: who are the radicals and whether counter- radicalisation extends to sympathy for terrorist causes, a belief that Islam is incompatible with democracy, support for the application of Shari'a law or support for the Islamic caliphate: all ideas associated with the ideologies of extremist groups such as Hizb ul Tahrir.

In concurrence with arguments against the marginalisation hypothesis and the primacy of religion, Richards suggests that the focus on radicalisation conflates social cohesion policies with counterterrorism responses under the assumption that addressing social, political or economic inequalities is a panacea for terrorism. Further, identifying particular groups, namely Muslims, as being more vulnerable to radicalisation is largely based on the assumption that religion is the primary driver for extremist violence. Assuming that vulnerability to radicalisation is the primary marker for identifying potential terrorist threats risks misinterpreting violent extremism as a manifestation of irrational or radicalised behaviour. The implication is that deradicalisation is the appropriate response for addressing the threat of terrorism. Yet individuals can be radicalised and never engage in violence. They may also continue to be radical even after disengaging with violent extremist groups.

\section{Narrow construction of the audience that terrorists seek to influence}


A common thread in the policy response to home-grown terrorism is a focus on the individuals and groups terrorists seek to influence for sympathy, support or recruitment. Consequently, the activities of Prevent and Resilience strategies single out Muslim communities identified as being most vulnerable to engaging with al Qaeda ideologies. This approach reflects a narrow construction of terrorism as primarily the actions of al Qaeda recruiters and propagandists to influence an audience of potential sympathisers and supporters. Regardless of the strategic or material goals of terrorism, all terrorists have a communicative objective of influencing, not one, but several groups of audiences.

Price (1977) identified three audiences in a hostage taking incident:

1. The immediate victim - the hostage;

2. The identification group—responsible for the welfare of the hostage; and

3. The resonant mass - the broader national population.

In hostage taking situations fear is focused on the hostages and the threat to their lives which is used to coerce the identification group into meeting the terrorists' demands. When the hostage is a high profile political, religious or business figure, the identification group may meet the terrorists' demand in order to avert a major crisis. In hostage taking situations that involve members of the public, fear also extends to the resonant mass that will pressure the identification group to resolve the situation. Price's analysis of the audiences in a hostage taking incident can be extended to all forms of terrorist activities with the addition of a fourth audience category:

1. The immediate victims of a terrorist incident;

2. The identification group of governments and/ or non-government bodies and/or communities responsible for the welfare of the immediate victims; 
3. The resonant mass of national and international populations that may witness the terrorist incident through the immediacy of the international media; and

4. The collective mass of sympathisers and potential recruits to the terrorist cause (Aly, 2011).

Prevent and Resilience strategies that have singled out Muslim communities identifying them as vulnerable to radicalisation and particularly susceptible to isolation and marginalisation engage only one dimension of the terrorists' audience profile. Apart from the problems with singling out Muslim communities already discussed, the narrow focus on the collective mass fails to effectively counter the terrorist influence. Increased security measures that threaten civil liberties may actually compound the terrorists' objective of instilling fear in the resonant mass. Public discontent at government counter terrorism measures that intrude on civil liberties can also exert considerable influence in democratic nations where governments are accountable to a voting public.

Adopting a broader conceptualisation of the terrorist audience that focuses not only on programs targeting the collective mass but also involve the resonant mass would refocus the policy response to one which promotes social resistance to terrorism based on the communicative objectives of terrorism.

\section{Collective action and counterterrorism}

At its core collective action aims to bring about social change. A broad definition of collective action is a group of individuals working towards a common goal. Van Zomeren and Iyer (2009) describe collective action as "any action that aims to improve the status, power or influence of an entire group, rather than that of one or a few individuals" (p. 646). For them, collective action applies in conditions where 
groups of individuals take action to address social inequalities such as discrimination or in conditions where groups take action to prevent inequalities. Van Zomeren and Iyer cite protests and demonstrations, petitions and voting as examples of collective action to address (or prevent) social inequality and injustice.

Collective action has also been applied to diverse problems ranging from civil rights to climate change and to diverse pursuits ranging from civil protests to institutional and state cooperative arrangements such as regional alliances. Indeed a vast array of phenomena can be analysed from a collective action perspective. In this sense, the simultaneous action of Australians turning their backs on former opposition leader Brendan Nelson in his response to the Prime Minister's Apology to the Aboriginal people constitutes collective action. So too, the self-organising online groups that drove the popular revolutions across the Middle East are also examples of collective action. At another level, regional alliances such as ASEAN, and international cooperative arrangements such as the Kyoto Protocol also constitute collective action. Collective action against terrorism is often interpreted as co-ordinated counter terrorism efforts by states, intergovernmental organisations and non-state actors such as NGOs. In this sense it is conceptualised primarily as formalised arrangements although the parties may act in ad-hoc, informal or improvised ways. Meanwhile, the literature on terrorism draws attention to the social situations in which public support for terrorism flourishes and asserts that support for dissident terrorist activities is garnered in contexts where social, political or economic inequalities exist. For this reason, international efforts to counter terrorism through soft approaches target economic development, political reform, and the promotion of social and political equality in countries where terrorist groups are known to have significant public support. On the home front, this interpretation of collective action against terrorism 
translates into the policy response to home-grown terrorism discussed in this paper. Collectively, the four assumptions of soft counter terrorism responses: marginalisation hypothesis; the primacy of ideology; a focus on radicalisation and; a narrow interpretation of audience, imply that terrorism can be countered by identifying and targeting individuals and groups assumed to be vulnerable to radicalisation because they are marginalised and hence more likely to engage with extremist ideologies. Community resilience to terrorism is therefore assumed to be achieved through the promotion of social harmony and common values: an approach concisely described by the Deputy Secretary for the US Department of Homeland Security, Jane Lute, in her 2011 address to the Council on Foreign Relations:

How do we prevent the potential terrorist? There's -- for every individual one, there's an individual story, but there is a counter-narrative. What al-Qaida and other terrorist groups are trying to do is create a sense of community, a sense of belonging, a sense of purpose and meaning. It's the wrong purpose, it's the wrong community, it's the wrong belonging and meaning. And counternarrative -- living the American way of life, making this a safe, secure, resilient place where all of us can pursue it -- is going to be key to what this department does every day in preventing the emergence of violent extremism.

Broadening the notion of collective action as it applies to counter terrorism may offer a solution to the criticisms levelled at the policy response to homegrown terrorism. This involves extending the concept of collective action to initiatives, both formal and informal, that have, as their primary goal, the construction of narratives of resistance to terrorism and the terrorists' communicative aim of influencing multiple audiences through coercion, intimidation and fear. Historically, there are many examples of terrorist groups either meeting their demise or abandoning violence in the face of collective resistance, demonstrating the potential impact that public resistance can have on terrorism. In the 1990's, two failed assassination attempts by the Islamic Jihad group resulted in the death of innocent bystanders, one a young school girl 
named Shayma. The failed operations damaged the public opinion and support for the Islamist groups and eventually contributed to the demise of Islamic Jihad in Egypt (Aly 2009). In contrast, there are few examples of government funded programs with a specific focus on harnessing collective resistance to terrorism as part of a comprehensive soft counterterrorism strategy. Examples that come closest are those that use principles borrowed from social marketing in the development of antiterrorism campaigns designed to influence public opinion and mobilise public attitudes against violent extremism (Aly, 2011). Interestingly, these campaigns have been initiated by governments in countries like Iraq, Pakistan and Saudi Arabia yet are notably absent in the counterterrorism programs of Australia, the UK and the United States.

\section{The Bali Peace Park: an example of collective resistance to terrorism}

The Bali Peace Park is an initiative by the Perth based Bali Peace Park Association Inc (BPPAI) ${ }^{\mathrm{i}}$ to develop the site of the 2002 Bali bombings in which 202 people died (among them 88 Australians). The BPPAI website states its Mission Statement as: To create a spiritual garden on the Sari Club site for persons to reflect upon and acknowledge the terrorist attack on October 12th 2002, along with all acts of terror worldwide. To help build a future without fear by promoting tolerance, understanding and freedom for generations to come, irrespective of nationality, culture, religious belief or race (www.balipeacepark.com.au).

The BPPAI was founded in 2008 by survivors, families and friends of the 2002 and 2005 terrorist attacks in Kuta. The Association receives ongoing support from the Governor of Bali and the Bupati of the Badung Regency and the Australian Federal 
and State Governments. Unlike many of the soft initiatives driven by the policy response to terrorism, the Bali Peace Park project does not directly target Muslim communities or groups assumed to be more vulnerable to radicalisation and violent extremism. Rather the project is entirely citizen driven and involves members of the various audiences of terrorism explicated earlier in this paper: immediate victims; identification group; resonant mass and collective mass.

The research study reported here used focus groups and individual interviews with Australian and Balinese survivors of the 2002 and 2005 terrorist attacks and members of the resonant and collective mass in Australia and Bali. The study aims to address the significant issue of developing social resilience to terrorism by exploring the ways in which the Peace Park initiative communicates a counter- narrative to terrorist propaganda and the utility of the park as soft counterterrorism. It also attempts to explore ways in which initiatives such as the Peace Park present a viable alternative to programs driven by the policy response to homegrown terrorism and its underlying assumptions.

The preliminary findings of the study highlight three key themes for consideration:

1. A collective identity among diverse and broad groups in Australia and Bali

2. Informal and formal collaborative participation of diverse stakeholders with diverse security interests

3. A strong focus on constructing a counter narrative to the terrorist attacks that communicates resistance to terrorism and its social impacts.

\section{Collective identity}

Diverse participants in the study expressed a sense of collective identity as members of the audience of the Bali terrorist attacks. In particular, this collective identity was not constructed in relation to their specific association with the attacks - as immediate 
victim or identification group — but is embedded in the collective memory of the Bali bombings. As one participant stated, the Bali bombings affected "Every community...I haven't found one community in Australia, whether it's a small town...there's some connection." Another participant articulated the nature of the bombings as a collective experience in the following excerpt: "when you discuss things with people they speak of the time there is always before the bomb and after the bomb. For the people that lived and worked there, the Balinese, that bomb event has gone into their understanding of time and event."

This theme is consistent with the findings of a previous study by the author which involved 180 participants in a qualitative study on Australian responses to international terrorist incidents. The former study found that the Bali bombings and the 2005 London terrorist attacks resonated strongly with Australian audiences because of the Australian connection to Bali as a popular tourist destination and its cultural kinship with the United Kingdom.

Among the local Balinese participants interviewed for the study, the sense of collective identity around the Bali bombings was based on the social and economic impacts of the bombings. Many participants referred to a time 'before Bom Bali' and a time 'after Bom Bali'. The distinction between these two eras was most often expressed in terms of the economic impact on tourism: "the biggest difference is economic. Before Bom Bali everything was cheaper and money was more easy to find so the people were happy. But after Bom Bali, about one year later, it was so quiet. And then a lot of people lost jobs until some people were so stressed they killed themselves".

\section{Collaborative participation}


While the Bali Peace Park project is citizen driven, the BPPAI, like other civil society groups is bound by the conditions for gaining recognition and legitimacy (Ostrom, 2005). These conditions require the strategic use of support from institutional actors (Ju and Tang, 2009). The BPPAI has co-opted support from the Balinese and Australian governments as well as high profile Balinese and local 'Ambassadors' for the project. The collaborative participation in formal and informal ways by institutional and non-institutional actors with diverse interests and agendas is reflective of new patterns of collective action in conflict management described by Crocker, Hampson and Aall (2011).

In December 2008, the UN Secretary-General, Ban KI-moon addressed the Security Council meeting on Global Security and International Terrorism stating that "The best response to a corrosive, malevolent ideology is a strong assertion of collective resistance" (United Nations, 2002). The acknowledgement of collective resistance as a key driver in combatting terrorism was, most likely, made with reference to traditional concepts of collective conflict management that involve formalised arrangements between international organisations and individual states. Nonetheless, the UN Secretary's assertion that collective resistance to terrorism should be the key driver of counterterrorism responses provides a useful starting point for reconceptualising soft counterterrorism as collective resistance and extending this to the complexity of the current security involvement that Croker, Hampson and Aall call for. The combination of formal and informal, grass roots and institutional in the Bali Peace Park example suggests that the broadened concept of collective conflict management can also be applied to in the counterterrorism context.

\section{Collective Resistance}


Perhaps the most relevant finding of the research study into the Bali Peace Park initiative is that, for those involved in the initiative as well as the local Balinese participants in the research, the Peace Park is a mechanism for collective resistance against terrorism. Collective Resistance is most often applied to social movements that contest systemic structural power through actions and oppositional behaviours such as protest, dissent, rebellion, strikes, work bans, absenteeism (Junor, O'Brien \& O'Donnell, 2009) or gang behaviour (Brotherton, 2008). The body of literature on collective resistance incorporates a wide range of phenomena such as the emergence of collective resistance in repressive environments (Mahe,r 2010), collective resistance against land use (Ju \& Tang, 2009), collective resistance and gang culture (Brotherton, 2008), collective identity (Polletta \& Jasper, 2001) protest theory (Dalton, Van Sickle \& Weldon, 2009) and anti-war activism (Gillan \& Pickerill, 2008).

In the aftermath of international terrorist incidents in the US, London and Bali, responses most often expressed a return to normality as a demonstration of resistance to terrorism: "let's go on as business and usual, let's stick it up the terrorists." These kinds of responses mirrored the Western political rhetoric which constructed counterterrorism as the defence of democratic values and "our way of life" (Australian Government, 2004, p.76) and translated collective resistance in terms of upholding liberal democratic values. Counter-narratives to terrorism were thus constructed as narratives that espoused the values of liberal democracy and rejected ideological influences that criticised the West. For the participants in the Bali Peace Park research, the Bali Peace Park represents much more than a return to the everyday and banal as evidenced in the following interview excerpts: 
The Peace Park needs to happen because if nothing happened there [the site of the bombings] and it became a car park, it became a restaurant and nightclub...it would be a victory for terrorism.

It [the Peace Park] is actually symbolically it's as strong an act as the act of terrorism itself but at the opposite end of the spectrum...If you don't do anything about it [terrorism] you're actually tacitly saying it was OK in a way: tacitly moving your eyes over it.

It is definitely making a statement that life is going on ...but it is more than just life going on, it's actually as life progresses this is something good and something that is actually being created.

Among the local Balinese participants interviewed for the study, collective resistance to terrorism was also expressed in terms of heightened community awareness and security. The Balinese participants interviewed expressed overwhelming support for the construction of a Peace Park on the site of the former Sari Club. For these participants the Peace Park represents a means of marking time before and after Bom Bali. Many expressed a fear that building a restaurant or club on the site of the former Sari Club would only attract another terrorist attack, while a Peace Park would not be an attractive target for terrorism. The Peace Park, symbolising the peaceful relations between Balinese of different religious beliefs and traditions, would also serve to communicate a counter narrative to terrorism and as a preventative measure:

"I think it [the Peace Park] give a message because they [terrorists] will see it and they will think again 'oh maybe if I try to bomb again maybe it doesn't work' so they will think of another way to get what they want". 
"It [the Peace Park] would make a lot of people think about peace. I mean if we want to counter the terrorists maybe we can think more about peace or you know natural things".

In the field of terrorism studies, resistance is most often applied to causal analyses of terrorism as an instrument of counter-hegemonic movements. The application of a collective resistance framework to soft counterterrorism has, thus far, eluded academics and policy makers alike. Collective resistance may offer a useful alternative framework to inform the development of counterterrorism approaches such as Prevent and Resilience by focussing these approaches on programs that construct counter- narratives of resistance as opposed to narratives of social harmony or religious tolerance. While the interviews with local Balinese and Australians affected by the Bali bombings express some dimensions of a social harmony and tolerance narrative, they were clearly framed as resisting terrorism through active engagement with initiatives such as the Bali Peace Park that harness collective identity, are collaborative in nature and that are conceptualised as a platform for communicating resistance to the social impacts of terrorism. The Bali Peace Park may also communicate social harmony and religious tolerance, but in the minds and hearts of those involved and the local Balinese community, its significance is firmly rooted in the event of the Bali terrorist attacks.

\section{Conclusion: Reconceptualising the policy response to home-grown terrorism}

Despite their flawed assumptions, both the marginalisation approach and the promoting moderate Islam have a place in the broader social policy context. There is significant value in encouraging and promoting social harmony, equality and active participation by all citizens and the contribution of initiatives in these areas should not 
be underestimated. Similarly efforts to enable the voices of the majority of 'moderate' Muslims should be encouraged. Whether such approaches are effective in preventing home grown terrorism and countering violent extremism and how such effectiveness can be measured however are questions that deserve consideration.

Efforts have already been made to separate the core functions of countering terrorism from that of promoting social harmony and tackling marginalisation. The recent review of the UK's Prevent strategy recommended a re-focus of Prevent and a separation of the Prevent remit from programmes that focus on race equality, multiculturalism and cohesion. In Australia, the National Action Plan to build Social Cohesion, Harmony and Security was divulged to the Australian Human Rights Commission under a new program with a focus on building resilience, addressing social exclusion and supporting community safety in vulnerable communities. The Department of Immigration and Citizenship that had the initial remit for the National Action Plan continues to support community engagement through its Diversity and Social Cohesion Program. The remit for countering violent extremism now sits with the Attorney General's Department and is implemented through the Building Community Resilience Grants Program which supports community projects that build resilience to violent extremism. While these measures represent attempts to address some of the problems associated with the marginalisation hypothesis, they may yet fall short of actually reframing the agenda of Prevent and Resilience in any meaningful way. The new Prevent strategy is largely focussed on radicalisation, ideology and vulnerability of the collective mass. In Australia, the community resilience approach, while a significant departure from the social cohesion approach of the previous government, likewise retains a primary focus on a nebulous understanding of radicalisation, the role of ideology and the assumption of 
vulnerability. It also continues to focus on marginalisation as a root cause of violent extremism and to encourage political participation. In light of this, the re-focus of Prevent and Resilience may prove to be cosmetic and have little, if any, practical significance.

A re-conceptualisation of counterterrorism approaches of Prevent and Resilience requires a new paradigm of thinking about the assumptions upon which these policy responses are based. Soft counterterrorism constitutes an important and necessary element of a comprehensive counter terrorism strategy both internationally and on the home-front. An alternative framework for developing soft counterterrorism starts from acknowledging that terrorists have an objective of influencing multiple audiences and that these audiences, individually and collectively, have agency in constructing counter narratives to terrorism. From this basis, we can begin to build a policy response that promotes collective resistance to terrorism involving multiple audiences in meaningful ways. 


\section{References}

Aho, J. (2006). Christian Fundamentalism and Militia Movements in the United

States. In J. Forest, ed. The Making of a Terrorist: Recruitment, training, and root causes, London: Praeger Security International.

Aly, A. (2009). The Historical Roots of Al Qaeda's Ideology: Understanding Ayman al Zawahri's Vision and Developing an Appropriate Response'. In S. Brawley, ed. Doomed to Repeat: Terrorism and the Lessons of History(115-133), Canberra: New Academia Press

Aly, A. (2011).Terrorism and Global Security: Historical and Contemporary Perspectives. Melbourne: Palgrave Macmillan

Al Zawahiri, A. (2006). Knights under the Prophet's Banner. In His Own Words: A translation of the Writings of Dr. Ayman al Zawahiri, trans. L. Mansfield. USA: TLG Publications

Australian Government, Attorney Generals Department. n.d. Building Community

Resilience Grants Program. Retrieved from

http://www.ag.gov.au/www/agd/agd.nsf/Page/Nationalsecurity_CounteringViolentExt remism_BuildingCommunityResilienceGrantsProgram

Australian Government, Department of Foreign Affairs and Trade. (2004).

Transnational Terrorism and the threat to Australia. Canberra: Commonwealth of Australia.

Bowers, P. (2011). Review of the Prevent strategy. Parliament and Constitution Centre.

Commonwealth of Australia, Department of Immigration and Citizenship. The National Action Plan. Available at: http://www.immi.gov.au/living-in-australia/adiverse-australia/national-action-plan/nap.htm 
Brotherton, D. C. (2008). Beyond social reproduction: Bringing resistance back in gang theory. Theoretical Criminology, 12 (1), 55-77.

Crenshaw, M. (1981). The Causes of Terrorism. Comparative Politics, 13(4), 379399.

Crenshaw, M. (2003). The Causes of Terrorism. In C. Kegley, ed. The New Global Terrorism: Characteristics, causes, control. Upper Saddle River: Prentice Hall.

Crocker, C., F. Hampson, and P. Aall. (2011). Collective conflict management: a new formula for global peace and security cooperation? International Affairs, 87 (1), 3958.

Council on Foreign Relations (2011). Transcript: Community Partnerships to Counter Violent Extremism. Symposium on UK and U.S. Approaches in Countering Radicalization: Intelligence, Communities, and the Internet . April 1, 2011, Washington, D.C. Available at http://www.cfr.org/uk/community-partnerships$\underline{\text { counter-violent-extremism/p24593 }}$

Dalton, R., Van Sickle, A., and Weldon, S. (2009). The Individual- Institutional nexus of protest behaviour. British Journal of Political Science, 40, 51-73.

Department of Homeland Security: Office of Intelligence and Analysis Assessment. (2009). Rightwing Extremism: Current Economic and Political Climate Fuelling Resurgence in Radicalization and Recruitment.

Department of Prime Minister and Cabinet. (2010). Counter Terrorism White Paper: Securing Australia, Protecting our Community.

Duffy, D. (2009). Alienated radicals and detached deviants: What do the lessons of the 1970 Falls Curfew and the alienation-radicalisation hypothesis mean for current British approaches to counter- terrorism? Policy Studies, 30(2), 127-142. 
Gillan, K., and Pickerill, J. (2008). Transnational Anti-war activism: Solidarity, diversity and the internet in Australia, Britain and the United States after 9/11. Australian Journal of Political Science, 43 (1), 59-78.

Gurr, T. (1970). Why men rebel. Princeton: Princeton University Press.

Hancock, N. (2002). Terrorism and the law in Australia: Supporting Material.

Canberra: Department of the Parliamentary Library.

House of Commons. (2006). Report of the Official Account of the Bombings in London on 7th July 2005. London: House of Commons.

Intelligence and Security Committee. (2006). Report into the London Terrorist Attacks on 7 July 2005.London: Intelligence and Security Committee

Ju, C., B and Tang, S. (2009). External legitimacy, goal congruence, and collective resistance: Environmental NGOs and land use politics in South Korea. Environment and Sustainability WP -November 2009-1, 1-33

Junor, A., O’Brien, J., and O’Donnell, M. (2009). Welfare wars: Public service frontline absenteeism as collective resistance. Qualitative Research in Accounting and Management, 6 (1/2), 26-40.

M2 Presswire (2008) United Nations: Strong Collective Resistance Is Best Response To 'Corrosive, Malevolent Ideology' Of Terrorism, Secretary-General Tells Security Council Meeting. Retrieved from http://www.proquest.com.dbgw.lis.curtin.edu.au/ Maher, T.V. (2010). Threat, resistance and collection action: the cases of Sobibor, Treblinka and Auschwitz. American Sociological Review, 75 (2), 252-272.

Malley, R., and Harling, P.(2010). Beyond Moderates and Militants. Foreign Affairs 89(5), 18-29.

National Bureau of Asian Research. (2007). NBR Panel at ICAS5: Approaches to 'Moderate' Islam in Asia: The Dynamics among Islam, Muslim Identity, Politics, and 
Society in Asia. Retrieved from

http://www.nbr.org/Downloads/pdfs/PSA/Moderate_Conf07.pdf

Oberschall, A. (2004). Explaining Terrorism: The contribution of collective action theory. Sociological Theory, 22 (1), 26-37

Ostrom, E.(2005). Understanding Institutional Diversity. Princeton, NJ: Princeton University Press

Pape, R. (2006) Dying to Win: Why suicide terrorists do it. London: Gibson Square Perl, R. (2005). US Anti Terror strategy and the 9/11 Commission Report CRS Report for Congress. Washington: Library of Congress.

Polletta, F., and Jasper, M. J. (2001). Collective identity and social movements. Annual Review of Sociology, 27, 283-305.

Price, H.E. (1977). The Strategy and Tactics of Revolutionary Terrorism.

Comparative Studies in Society and History, 19(1)1, 52-66

Rabasa, A. , Benard, C., Schwartz, L., and Sickle, P. (2007). Building Moderate Muslim Networks. Santa Monica, CA: RAND Corporation.

Richards, A. (2010). The problem with 'radicalization': The remit of 'Prevent' and the need to refocus on terrorism in the UK. International Affairs, 87(1),143-152.

Sageman, M. (2008). Leaderless Jihad: Terror Networks in the Twenty-first Century. Philadelphia: University of Pennsylvania Press.

Schwartz. D. (1973). Political alienation and political behaviour. Chicago:Aldine.

Stevens, D. (2009). In Extremis: a Self-defeating element in the 'Preventing Violent Extremism' strategy. The Political Quarterly, 80(4),517-525.

Thomas, P. (2009). 'Between two stools? The government's 'Preventing Violent Extremism' agenda. The Political Quarterly, 80 (2),168-171. 
Thornberry, T.P., Krohn, M.D., Lizotte, A.J., Smith, C.A., and Tobin, K. (2003).

Gangs and delinquency in developmental perspective. Cambridge: Cambridge University Press.

United Nations. n.d. UN Actions to Counter Terrorism: Strategy Highlights. Available at http://www.un.org/terrorism/strategy-highlights.shtml

United States of America Government. (2010). National Security Strategy 2010.

Available at

http://www.whitehouse.gov/sites/default/files/rss_viewer/national_security_strategy.p

$\underline{\mathrm{df}}$

Victoroff, J. (2005). Mind of the Terrorist: A Review and critique of psychological approaches. The Journal of Conflict Resolution, 49 (1),3-42

${ }^{\mathrm{i}}$ The author was appointed the Western Australian Ambassador for the Bali Peace Park by the BPPAI in 2011. 